\title{
MAATALOUSTRAKTORIEN KUNNOSSAPITOKUSTANNUKSESTA
}

\author{
ERKKi H. OKSANEN \\ Maanviljelystaloudellinen laitos, Helsingin yliopisto
}

Saapunut 12.9. 1956

Traktoria pidetään koneellistetun maatalouden peruskoneena. Sitä sopivien työkoneiden kanssa oikein käyttäen on mahdollista saavuttaa työajan ja -kustannusten säästöä. Traktorin käytöstä aiheutuu kuitenkin määrättyjä kustannuksia, jotka tavallisesti jaetaan perus- ja käyttökustannuksiin (vrt. 4). Edellisiin kuuluvat poisto-, korko-, säilytys-, vakuutus-, vero- ja kunnossapitokustannukset, sekä jälkimmäisiin ajajan palkka ja poltto- ja voiteluainekustannukset.

Traktorin käytöstä johtuvia kustannuksia laskettaessa joudutaan turvautumaan arviolukuihin. Ajajan palkka, poltto- ja voiteluainekustannukset, säilytys-, vakuutus-, vero- ja korkokustannukset ovat suhteellisen helposti arvioitavissa ja laskettavissa. Sensijaan poisto- ja kunnossapitokustannusten arvioiminen on huomattavasti vaikeampaa. Traktoreiden nopean kehittymisen ja käyttömuotojen lisääntymisen sekä muuttumisen johdosta eivät loppuunkäytettyjen traktoreiden työ- ja kustannuslaskentakirjoista saatavat luvut täysin sovellu perusteiksi uusien traktoreiden kustannuslaskelmiin, puhumattakaan hinta- ja palkkatason vaihtelun aiheuttamasta kustannusten muuttumisesta.

Poisto- ja kunnossapitokustannukset liittyvät toisiinsa mm. sikäli, että mitä kauemmin traktoria korjataan, sitä suuremmaksi nousee kunnossapitokustannus, mutta käyttöajan pitenemisen johdosta vuotuinen poistokustannus alenee. Sen laskemisessa edellytetään tavallisesti traktorille tietty käyttöikä määrätyn suuruisella vuotuisella käytöllä (vrt. esim. 2).

Traktorin kunnossapitokustannusta on vaikea tarkasti selvittää. Siihen kuuluvat, paitsi varsinaista korjauskustannusta, myös erilaiset säädöt ja perusteelliset puhdistukset. Traktorin päivittäinen huolto, joka sisältää polttonesteen täytön, rasvauksen, öljyjen vaihdon, jäähdytysnesteen sekä öljymäärän tarkistuksen ja lisäyksen, akun ja renkaiden huollon, pikku puhdistukset jne., lasketaan useimmiten 
kuuluvaksi ajajan päivittäisiin tehtäviin ja pidetään näinollen varsinaisen kunnossapidon ulkopuolella käyttökustannuksiin kuuluvana eränä (vrt. 6). Traktorinajajan taitavuudesta ja harrastuksesta, työvälineiden saatavillaolosta, korjauksen kiireellisyydestä yms. riippuu, kuinka suuri osa traktorin varsinaisesta kunnossapitotyöstä suoritetaan tilalla omin voimin.

Kunnossapitokustannuksen suuruuteen vaikuttavat ratkaisevasti myös sellaiset tekijät kuin traktorin koko ja moottorityyppi, vuotuinen käyttömäärä,suoritettujen töiden laatu, ajotapa, huollon ja korjauksien kunnollisuus sekä aikanaan suorittaminen, traktorin säilytys, ilmasto, ja kauanko traktoria katsotaan kannattavan korjata.

Uuden traktorin kunnossapitokustannus on pieni, mutta se suurenee käyttöiän kasvaessa. Schaefer-Kehnert (5) olettaa kunnossapitokustannusten kasvun olevan tasaisen. Tätä vastaan puhuu mm. Hollannissa suoritettu tutkimus, joka käsitti satoja valtion tiloilla ennen toista maailmansotaa käytössä olleita traktoreita. Näiden korjauskustannus vaihteli vuodesta toiseen huipun sattuessa $n$. viidennen käyttövuoden kohdalle (8). Englannissa suoritetun arvion mukaan on sodanjälkeisten Fordson-Major traktoreiden kunnossapitokustannuksissa kaksi huippua, ensimmäinen $3-4$ ja toinen $7-8$ käyttövuosien kohdalla (1).

Traktorin kunnossapitokustannus lasketaan tavallisesti käyttötuntia kohden. Sen suuruudesta oloissamme on REINIKAINEN (4) esittänyt arvion:

$\begin{array}{lcrl}\text { dieseltraktorit } & \text { suhdeluku } & 100 & 35:- \text { tunti } \\ \text { petrolitraktorit } & " & 90 & 32:-/ \text { tunti } \\ \text { bensiinitraktorit } & " & 85 & 30:- \text { tunti } \\ \text { hehkukuulatraktorit (1-syl.) } & \text { " } & 75 & 29:- \text { tunti }\end{array}$

LÖNNEMARK (2) katsoo dieseltraktorin kunnossapitokustannuksen nousevan $25 \%$ korkeammaksi bensiini- tai petrolimoottorisen traktorin kunnossapitokustannusta. Hän esittää myös käyttötuntia kohden laskettavan kunnossapitokustannuksen suuremmaksi vuosittain vähän käytettävälle traktorille seuraavien esimerkkilukujen tapaan:

\section{Vuotuinen käyttö tuntia}

300

500

700

900

$\begin{array}{cr}\text { kruunua/tunti keskikokoiselle } \\ \text { kaasutin- } & \text { diesel- } \\ \text { traktorille } & \text { traktorille }\end{array}$

1.80

1.50

1.30

1.15
2.25

1.90

1.60

1.40

Ruostumisen, kylmäsyöpymisen, kumiosien pykimisen, jousien kuoleutumisen yms. seikkojen johdosta tulee traktoriin vikoja käyttämättömänäkin. Myös eräät vuosittain suoritettavat tarkistukset nostavat vähän käytettävän traktorin kunnossapitokustannusta. 


\section{Traktorinosien kestoiän arvioinnin perusteella laskettu korjauskustannus}

Maataloustraktorien eri osien kestosta on ammattimiehillä jo melko varmoja käsityksiä. Tähän perustuen on kirjoittaja laskenut traktorin korjauskustannuksen siten, että asiantuntijalautakunnilta on saatu arviot osien kestoajoista sekä asennustyön määrästä, ja liikkeiltä on saatu tiedot tarvittavien vara- ja vaihto-osien hinnoista (3).

Asiantuntijalautakuntiin on kuulunut Maatalouskoneiden tutkimuslaitoksen sekä traktoreita myyvien liikkeiden henkilökuntaa. Lähtökohtana traktorinosien kestoajan arvioinnissa on pidetty seuraavia käyttöolosuhteita:

- traktoria käytetään pääasiassa maatilatalouden töissä

- traktoria ei ylirasiteta

- traktorinajaja suorittaa itse jokapäiväisen huollon ja pienehköt säädöt

- traktorin vuotuinen keskimääräinen käyttö on 500 tuntia

— traktorin käyttöikä on 12 vuotta, minkä jälkeen sillä on vielä jälleenmyynti- tai romuarvoa $10 \%$ uudisarvosta.

Ottaen huomioon sodanjälkeiset maassamme yleisimmin esiintyneet 4-pyörämaataloustraktorit on suoritettu seuraava jako tehon ja moottorityypin perusteella:

- pienet kaasutinmoottoriset

$$
\begin{aligned}
& (10-20 \mathrm{hv}) \\
& (20-30 \mathrm{hv}) \\
& (20-30 \mathrm{hv}) \\
& (\text { yli } 30 \mathrm{hv})
\end{aligned}
$$

— keskikokoiset kaasutinmoottoriset

— keskikokoiset dieselmoottoriset

- suuret dieselmoottoriset

Suluissa mainitut luvut tarkoittavat ko. traktoreiden hihnapyörätehoja. Bensiinija petrolimoottorisia traktoreita ei ole otettu alaryhmiksi, vaan ne ovat yhdessä kaasutinmoottoristen traktoreiden nimikkeellä.

Traktorin korjauskustannuksissa voidaan eroittaa kaksi pääryhmää; uusinnat ja korjaukset. Ensinmainittuun sisältyvät osat, joita ei korjaamalla voida aina kunnostaa, kuten esim. renkaat, akku, lamput ja öljynsuodatinpakkaus. Toiseen ryhmään sisältyvät osat, mitkä saadaan korjaamalla uuden- tai lähes uudenveroisiksi, esim. jarrut, kytkin ja mottori.

Kuultujen asiantuntijalautakuntien mielipiteet uusinnoista ja korjauksista olivat lähes yhdenmukaiset etenkin suurimpien kustannuserien kohdalla. Varaosien hinnoittelu samaa suuruusluokkaa olevilla erimerkkisillä traktoreilla oli myös jotakuinkin yhtenäinen. Korjauksien työkustannusta laskettaessa olivat useille töille määrätyt urakkahinnoittelut suurena apuna. Näiden puuttuessa on työkustannus laskettu ammattitaitoisen asentajan tuntipalkan ja arvioidun työajan perusteella. Asentajan työtunnin veloituksena on käytetty 400 markkaa. Paitsi varaosia tarvitaan korjauksissa usein myös hitsauspuikkoja tai -kaasua, maalia, juottotinaa, paikkarautaa yms. Näistä yhdessä varaosien kanssa muodostuu uusintojen ja korjausten tarvikkeet. Yhteenvetona yksityiskohtaisten arvioiden perusteella lasketuista traktorin korjauskustannuksista saatiin taulukossa 1 esitettävät määrät. 
Taulukko 1. Pienen ja keskikokoisen kaasutintraktorin sekä keskikokoisen ja suuren dieseltraktorin arvioidut korjauskustannukset 500 tunnin vuotuisella käytöllä 12 käyttövuoden kuluessa.

Table 1. Estimated repair costs of a small and a medium tractor with petrol or paraffin engine and of a medium and a large diesel tractor, when the yearly use amounts to 500 hours and the life of the tractor is 12 years.

\begin{tabular}{|c|c|c|c|c|}
\hline & \multicolumn{2}{|c|}{$\begin{array}{l}\text { Kaasutintraktori } \\
\text { Tractor with petrol or } \\
\text { paraffin engine }\end{array}$} & \multicolumn{2}{|c|}{$\begin{array}{l}\text { Dieseltraktori } \\
\text { Dieseltractor }\end{array}$} \\
\hline & $\begin{array}{l}\text { Pieni } \\
\text { Small }\end{array}$ & $\begin{array}{l}\text { Keskik. } \\
\text { Medium }\end{array}$ & $\begin{array}{l}\text { Keskik. } \\
\text { Medium }\end{array}$ & $\begin{array}{l}\text { Suuri } \\
\text { Large }\end{array}$ \\
\hline $\begin{array}{l}\text { Uusintojen tarvikkeet } \mathrm{mk} \ldots \ldots \ldots \ldots \ldots \ldots \\
\text { Accessories for renewals } \mathrm{Fmk}\end{array}$ & 104740 & 130595 & 182340 & 225510 \\
\hline $\begin{array}{l}\text { Korjauksien tarvikkeet } \mathrm{mk}_{\mathrm{k}} \quad \ldots \ldots \ldots \ldots \ldots \ldots \\
\text { Accessories for repairs Fmk }\end{array}$ & 72640 & 88240 & 69740 & 76450 \\
\hline Työkustannus mk $\quad \ldots \ldots \ldots \ldots \ldots \ldots \ldots$ & 73400 & 79000 & 84600 & 89000 \\
\hline Yht. - Total & 250780 & 297835 & 336680 & 390960 \\
\hline $\begin{array}{l}\text { Kustannus käyttötuntia kohden mk } \quad \ldots \ldots \ldots \\
\text { Cost per hour of use Fmk }\end{array}$ & $41: 80$ & $49: 64$ & $56: 11$ & $65: 16$ \\
\hline $\begin{array}{l}\text { Työkustannusten osuus \% korjauskustann. . . } \\
\text { Percentage of cost of work of repair costs }\end{array}$ & 29.3 & 26.5 & 25.1 & 22.8 \\
\hline $\begin{array}{l}\text { Traktorin noin-hinta } \mathrm{mk} \quad \ldots \ldots \ldots \ldots \ldots \ldots \ldots \\
\text { Approximate price of tractor } F m k\end{array}$ & 310000 & 365000 & 415000 & 480000 \\
\hline $\begin{array}{l}\text { Korjauskustannukset } \% \text { traktorin hinnasta.... } \\
\text { Percentage of repair costs of the price of the tractor }\end{array}$ & 80.9 & 81.6 & 81.1 & 81.5 \\
\hline
\end{tabular}

Traktorin suuretessa on korjauskustannus arvioiden mukaan noussut. Dieseltraktorin korjauskustannus on samankokoisen kaasutintraktorin korjauskustannusta suurempi, mutta ero rajoittuu n. 13 prosenttiin. Työkustannuksen osuus nousee n. 25 prosenttiin korjauskustannuksista. Pienellä traktorilla tämä prosenttiluku on suurempi kuin isolla traktorilla. Tämä johtuu siitä, että pienen traktorin korjauksessa on työtä lähes yhtä paljon kuin isommankin, mutta varaosat pienempinä ja ehkä halvemmasta materiaalista valmistettuna ovat alempihintaisia. Korjauskustannukset nousevat arvion mukaan n. 81 prosenttiin uuden traktorin hinnasta.

Suurimpana kustannuseränä ovat traktorin renkaat, joista arvioitiin uusittavan molemmat taka- ja yksi etupäällysrengas sekä yksi taka- ja etusisärengas. Tämä muodostaa n. neljäsosan korjauskustannuksista. Akku aiheuttaa huomattavan menoerän vallankin dieseltraktorille; n. 10 mk käyttötuntia kohden. Moottorikorjauksesta koituu kaasutintraktorille yli $10 \mathrm{mk}$ ja dieseltraktorille 8-9 markan kustannuserä käyttötuntia kohden. Hydraulilaite kaikkine osineen aiheuttaa 2-3 markan korjauskustannuksen ajotuntia kohden. Dieseltraktorin polttoainejärjestelmästä koituva yli 8 markan korjauskustannus ajotuntia kohden johtuu suurelta osalta ruiskutuspumpun ja sumuttimien tarkistus- ja säätötyöstä.

Korjauskustannusten lankeaminen eri käyttövuosien osalle käy selville piirroksesta 1. $7-8$ käyttövuoden vaiheilla joudutaan uusimaan renkaat sekä suoritta- 
$\%$ korjauskustannuksista
$\%$ of repair costs

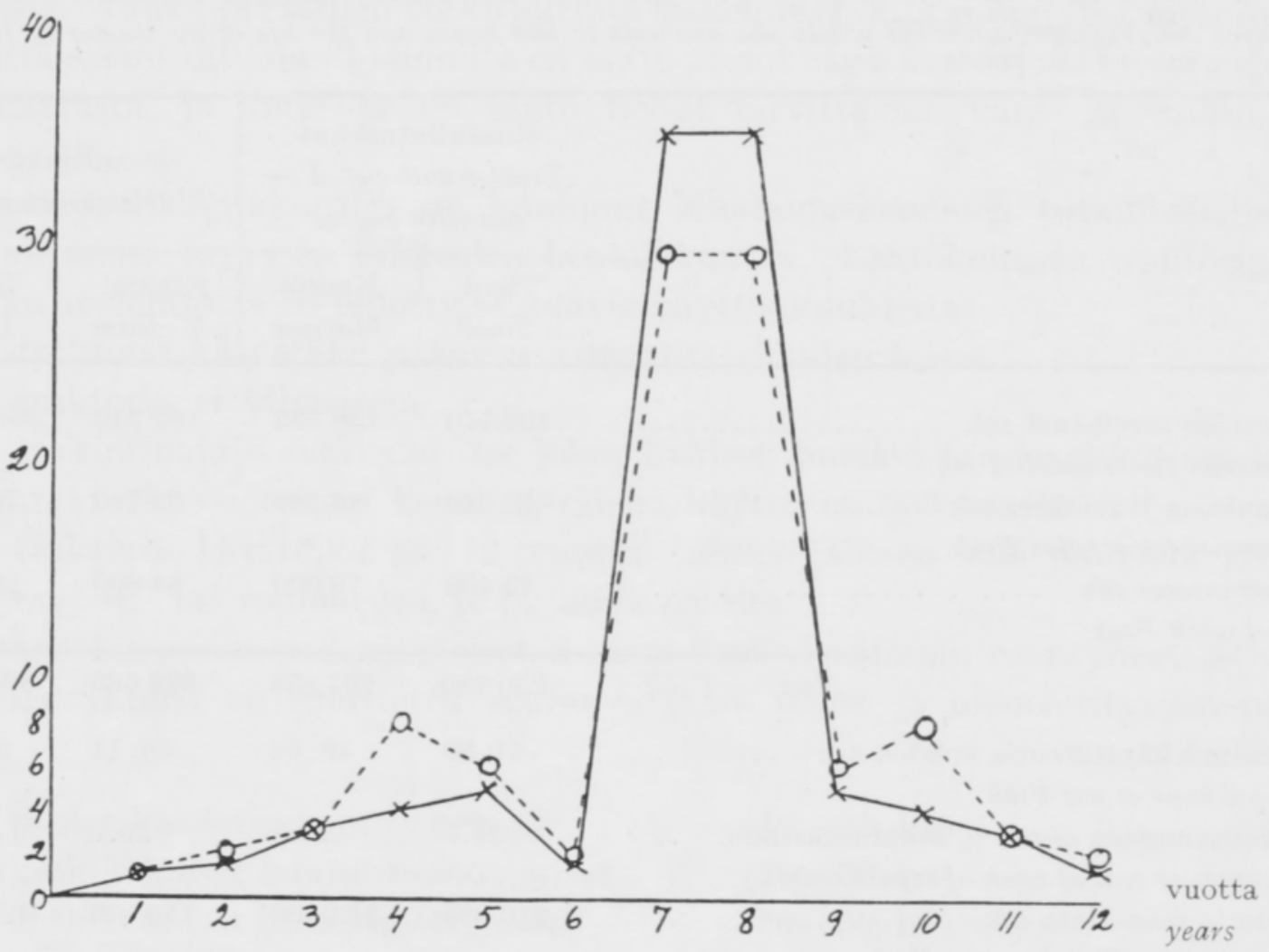

Piirros 1. Kaasutin- ja dieseltraktorin korjauskustannuskäyrä.

Fig. 1. Curve of repair costs of a tractor with petrol or paraffin engine and of a diesel tractor.

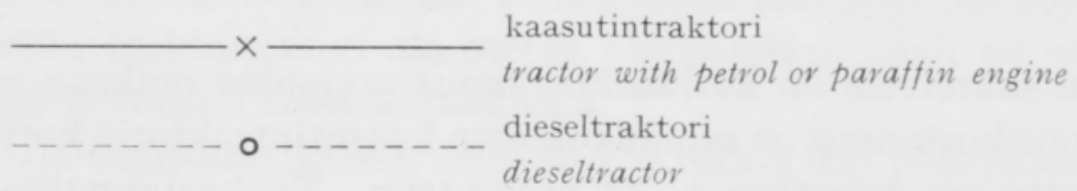

maan suurehko moottorikorjaus, hankkimaan toisen kerran akku sekä uusimaan mittareita ja sähköjohtoja, myös korjaamaan jäähdytys- ja voimansiirtojärjestelmän sekä ohjaus- ja hydraulilaitteen osia. Mainittujen vuosien kohdalle lankeaakin n. $70 \%$ kaasutin- ja n. $59 \%$ dieseltraktorin korjauskustannuksista.

Dieseltraktorin korjauskustannuskäyrä eroaa kaasutintraktorin vastaavasta käyrästä huomattavasti neljännen ja kymmenennen käyttövuoden kohdalla, mitkä ovat dieseltraktoreissa kalliin akun hankintavuosia. Toisaalta ei huippu kohoa niin korkealle kuin kaasutintraktorilla, koska dieselmoottori kestävämpänä ei vaadi niin perusteellista täyskorjausta kuin kaasutinmoottori. Lähinnä polttoainejärjestelmän säädöistä ja tarkistuksista johtuen nousevat normaalit vuotuiset korjauskustannukset dieseltraktorilla suuremmiksi kuin kaasutintraktorilla sekä markkamääräisesti että korjauskustannuskäyrässä prosenttuaalisesti.

Käytännössä on tietenkin mahdollista pitkittää eräiden uusintojen ja korjausten suorittamista, tai tehdä lähes kaikki 7 -8 käyttövuosien vaiheilla esiintyvät kor- 
jaukset ja uusinnat samalla kertaa. Korjauskustannuskäyrän yleinen muoto ei näistä johtuen kuitenkaan suuresti muutu, huippu vain tasottuu jonkin verran tai kärjistyy entisestään.

\section{Traktorin kunnossapitokustannus}

Kuten aiemmin mainittiin, kuuluu ajajan suorittama kunnossapitotyö korjauskustannusten lisäksi traktorin kunnossapitokustannuksiin. Tämä on kirjoittajan suorittaman tutkimuksen mukaan noussut lähes kymmeneen prosenttiin kunnossapitokustannuksesta viidellä maataloushallituksen kahdenkertaista kirjanpitoa pitävällä tilalla ja eräillä yksityistiloilla (3). Mainitut kirjanpitotilojen ja yksityisten tilojen traktoreiden kunnossapitokustannukset vuosina 1948 - 55 ovat olleet 25 - 48 mk käyttötuntia kohden. Tutkimuksessa mukanaolleista traktoreista oli vain pieni osa niin vanhoja, että ne olisivat läpikäyneet suurkorjauksen. Lisäksi on ollut eräitä tilakohtaisia kunnossapitokustannusta alentavia tekijöitä sekä hintojen ja palkkojen nousu, mitkä kaikki ovat olleet vaikuttamassa aiempien vuosien kunnossapitokustannuksien alhaisuuteen. Näinollen voidaan katsoa, että edellä selostettua arviolaskelmaa tukevat käytännöstä saadut tulokset.

Eräiden traktoreita myyvien liikkeiden antamasta aineistosta on laskettu varaosia myydyn vuosina 1953-55 keskimäärin lähes 10000 markan arvosta käytössä olevaa traktoria kohden (3). Vaihtelu eri myyntipiirien ja traktorimerkkien kesken on sangen suuri eli $2000-25000$ markkaan piirissä olevaa määrätynmerkkistä traktoria kohden. Paitsi traktorien koko, ikä ja moottorityyppi on varaosamenekkiin vaikuttanut selvästi myös traktorien käytön runsaus ja ankaruus. Sekä liikkeiden aineistosta saadut tiedot että maataloushallituksen kirjanpitotiloilta traktoreiden käytöstä tilivuosina $1953-54$ ja $1954-55$ saadut tiedot viittaavat siihen, että traktoreita käytetään sisä-, itä- ja pohjois-Suomessa enemmän kuin varsinaisilla maanviljelysseuduilla, ja että siellä käyttö on ankaraa, esim. uudis- ja kivenraivausta sekä metsätöitä $(3,7)$. Kun otetaan huomioon traktorikannan nuoruus, voidaan katsoa, että traktoreita myyvien liikkeiden aineistosta saadut tiedot myös osaltaan täydentävät arvioita traktorin korjauskustannuksista. Arvion mukaan olisi esim. keskikokoisen kaasutintraktorin vuotuinen tarvikekustannus 18240 : Liikkeiden myymät tällaiset traktorit ovat etupäässä $1-9$ vuoden ikäluokissa, joten osa niistä on jo läpikäynyt suurehkoja korjauksia. Varaosia on myyty vuosina 1953-55 käytössä ollutta po. traktoria kohden n. 15000 markan arvosta.

Näinollen on eri teitä päästy suhteellisen yhtenäiseen tulokseen traktorin kunnossapitokustannuksesta oloissamme. Arvion mukaiseen korjauskustannuslaskelmaan tulee lisätä aiemmin mainittu oman kunnossapitotyön osuus, jolloin saadaan erikokoisten traktoreiden kunnossapitokustannus käyttötuntia kohden vuotuisen käytön ollessa 500 tuntia ja käyttöiän 12 vuotta.

Kunnossapitokustannus käyttötuntia kohden alenee vuotuisen käyttömäärän kasvaessa, kuten aiemmin jo mainittiin. Perustuen tutkimusaineistona olleiden traktoreiden antamiin viittauksiin, kunnossapitokustannuksesta muista lähteistä saatuihin tietoihin ja traktorinosien kestoarvion läpikäyntiin erilaisilla vuotuisilla 
Taulukko 2. Eri traktorityyppien arvioidut kunnossapitokustannukset.

Table 2. Estimated maintenance costs of different types of tractors.

\begin{tabular}{|c|c|c|c|c|}
\hline \multirow{3}{*}{$\begin{array}{l}\text { Vuotuinen käyttö tunteja } \\
\text { Hours of use per year }\end{array}$} & \multicolumn{4}{|c|}{$\begin{array}{l}\text { Kunnossapitokustannus mk/käyttötunti } \\
\text { Maintenance costs } F m k / \text { hour of use }\end{array}$} \\
\hline & \multicolumn{2}{|c|}{$\begin{array}{c}\text { Kaasutintraktori } \\
\text { Tractor with petrol or paraffin engine }\end{array}$} & \multicolumn{2}{|c|}{$\begin{array}{l}\text { Dieseltraktori } \\
\text { Dieseltractor }\end{array}$} \\
\hline & $\begin{array}{l}\text { Pieni } \\
\text { Small }\end{array}$ & $\begin{array}{l}\text { Keskik. } \\
\text { Medium }\end{array}$ & $\begin{array}{l}\text { Keskik. } \\
\text { Medium }\end{array}$ & $\begin{array}{l}\text { Suuri } \\
\text { Large }\end{array}$ \\
\hline 400 & 50 & 59 & 67 & 78 \\
\hline 500 & 46 & 54 & 61 & 71 \\
\hline 600 & 43 & 50 & 57 & 66 \\
\hline 700 & 41 & 47 & 53 & 62 \\
\hline 800 & 39 & 45 & 51 & 59 \\
\hline 950 & 37 & 42 & 48 & 56 \\
\hline 1100 & 35 & 40 & 46 & 53 \\
\hline 1300 & 32 & 37 & 43 & 50 \\
\hline $\begin{array}{l}\text { Keskim. käyttö } \\
\text { Average use }\end{array}$ & 45 & 50 & 55 & 65 \\
\hline
\end{tabular}

käyttömäärillä on taulukossa 2 esitetty arvio kunnossapitokustannusten suuruudesta vaihtelevilla vuotuisilla käyttömäärillä. Taulukon viimeiselle riville on merkitty keskimääräistä käyttöä vastaavat kunnossapitokustannnusluvut lähimpään viiteen markkaan pyöristettynä. Luvut vastaavat n. $500-650$ tunnin vuotuista käyttöä, mikä todennäköisesti on maamme keskimäärää hivenen korkeampi.

Saadut luvut ovat ReINikAISEN (4) esittämiä n. $50 \%$ suuremmat, mihin ainakin osaksi on syynä rahanarvon aleneminen. Sensijaan Lönnemarkin (2) esittämät luvut ovat vähän suuremmat, joka johtunee siitä, että hän käyttää suuruusrajoissa 5 hv suurempia tehoja sekä laskee traktorille pitemmän käyttöiän, jolloin sitä joudutaan korjaamaan paljon varıhanakin, yli 12 vuoden ikäisenä.

Kun traktorin käyttöikäisistä kunnossapitokustannuksista saattaa yhden ainoan vuoden osalle tulla yli puolet, on selvää, että omistaja pyrkii myymään traktorin juuri ennen tätä suurkorjausta. Tällaisessa yksityistapauksessa voidaan kunnossapitokustannus laskea alhaiseksi, mutta poistot sensijaan on määrättävä suuriksi, sillä huonokuntoisella käytetyllä traktorilla ei ole normaaliolosuhteissa suurta myyntiarvoa. Sen ostaja joutuu suorittamaan korkeat kunnossapitokustannukset, mutta traktorin ostoon tarvittava alkupääoma on ollut pieni, joten poistot voi laskea alhaisiksi.

Traktorinosien keston perusteella laadittu arvio on verraten helposti tarkistettavissa, jos tarvetta muuttuneiden hinta- ja palkkasuhteiden johdosta esiintyy. Traktoreiden rakenteessa, lisävarusteissa, käyttömuodoissa ja -tavoissa tapahtuvat muutokset saattavat samoin aiheuttaa yksityiskohtien uudelleenarvioinnin. Kuten aiemmin on mainittu, nousee traktorin korjauskustannus arvion mukaan n. 81 prosenttiin uuden traktorin hinnasta ja näinollen kunnossapitokustannus n. 90 prosenttiin siitä. 
Traktorin kunnossapitokustannuksen laskemisessa on turvauduttava huomattavassa määrin arviointeihin. Perustuen asiantuntijalautakuntien suorittamiin arvioihin eri traktorinosien kestosta on laskettu korjauskustannus maatilakäytössä olevalle traktorille, jota käytetään keskim. 500 tuntia vuodessa 12 vuoden ajan. Korjauskustannusten huippu sattuu $7-8$ käyttövuosien vaiheille, jolloin ne muodostavat n. 2/3 traktorin käyttöikäisistä korjauskustannuksista.

Käytännöstä saadut kirjanpitotulokset tukivat em. arviota. Myös traktoreita myyvien liikkeiden antamasta, varaosien myyntiä eri myyntipiireissä koskevasta aineistosta saadut tiedot kävivät yhteen arvion kanssa. Liikkeiden aineiston ja maataloushallituksen kirjanpitotiloilta saatujen tietojen perusteella voidaan todeta traktorien käytön olevan runsaampaa ja ankarampaa sisä-, itä- ja pohjois-Suomessa kuin varsinaisilla maanviljelysseuduilla.

Kun korjauskustannukseen lisätään tilan omin voimin suoritettu kunnossapitotyö, joka nousee lähes kymmeneen prosenttiin kunnossapitokustannuksesta, saadaan eri kokoisille kaasutin- ja dieseltraktoreille seuraavat keskimääräistä käyttöä vastaavat kunnossapitokustannukset:

pieni $(10-20 \mathrm{hv})$ kaasutintraktori keskikokoinen $(20-30 \mathrm{hv})$ kaasutintraktori keskikokoinen $(20-30 \mathrm{hv})$ dieseltraktori suuri (yl $30 \mathrm{hv}$ ) dieseltraktori
45: - käyttötunti

50: - käyttötunti

55:- - käyttötunti

65: - käyttötunti

Dieseltraktorin kunnossapitokustannus nousee n. $13 \%$ vastaavankokoisen kaasutintraktorin kunnossapitokustannusta korkeammaksi.

Traktorin käyttöikäinen kunnossapitokustannus nousee n. 90 prosenttiin traktorin ostohinnasta. Kun yli puolet siitä voi langeta yhden tai parin käyttövuoden osalle, saattaa käytetyn traktorin ostaja joutua maksamaan täyskorjauksesta puolet uuden traktorin hinnasta.

\section{KIRJALLISUUTTA}

(1) D., A. F. 1952. Tractor running costs per year. Fordson Major E27N F5 (V. O.), Fordson Major E27N K391 (P6 diesel). Käsikirjoitus, $26 \mathrm{~s}$.

(2) Lönnemark, H. 1953. Beräkningar av kostnader och taxor för maskinarbeten i jordbruket. Jordbr. tekn. inst. medd. 251: $1-58$.

(3) OKSAnen, E. H. 1956. Traktorinkäytön peruskustannusosista ja erityisesti kunnossapitokustannuksesta. Käsikirjoitus, $123 \mathrm{~s} .+7$ liitettä.

(4) Reinikainen, A. 1954. Traktorikirja. 470 s. Helsinki.

(5) Schaefer-Kehnert, W. 1953. Zur Methodik der Kostenberechnung von Landmaschinen. Landtechnik 8: $616-621$.

(6) SipIL̈̈, M. 1949. Koneet maatilan organisatiossa. Työt.seur. julk. 58: 1-107. 
(7) Sirola, R. 1956. Kirjanpitotilojen tuloksia tilivuodelta 1954-55. Moniste, $33 \mathrm{~s}$.

(8) Widt, R. A. de \& Meer, W. C. van der. 1952. Trekkerkosten. Uitgave Inst. Landb.techn. Rat. 18: $1-30+4$ fig.

Sum mary:

\title{
ON MAINTENANCE COSTS OF FARM TRACTORS
}

\section{ERKKI H. OKSANEN}

\author{
Department of Agricultural Economics, University of Helsinki
}

When calculating the maintenance costs of a farm tractor one must lean in a great measure upon estimates. Basing on estimates over the durability of different parts of a farm tractor the writer has calculated the life time repair costs for a tractor, which is used 500 hours a year during 12 years. Tractors have been divided in four groups as to the size and type of engine:

- small tractor $(10-20$ H. P.) with petrol or paraffin engine

- medium tractor $(20-30 \mathrm{H}$. P.) with petrol or paraffin engine

- medium tractor $(20-30$ H. P.) with diesel engine

- large tractor (over 30 H. P.) with diesel engine

Table 1 shows the results of the calculation. According to the estimate, the peak of repair costs falls over the 7 th and 8 th year of use, as shown by fig. 1 .

The biggest item in repair costs is formed by tires, three of which are to be discarded. The purchase of new ones makes about one fourth of all repair costs.

Repair costs of a tractor with diesel engine are about $13 \%$ higher than those of a similar tractor fitted with petrol or paraffin engine.

Book-keeping results of tractors on farm use and the information obtained through firms selling tractors coincided with the above mentioned calculations.

When the maintenance work done over tractor on the farm, except daily service, is added to the repair costs of it, the total maintenance costs are obtained. According to tractor book keeping on some farms, the amount of maintenance work done on the farm amounts close to $10 \%$ of all maintenance costs.

Table 2 shows the estimated maintenance costs of farm tractors in Finland when the yearly use varies from 400 to 1300 hours of use.

The life time maintenance costs of a farm tractor amounts to about $90 \%$ of the price of a new tractor. Because over half of the costs may fall on one or two years, the buyer of a used tractor may have to pay half of the price of a new tractor for an overhaul.

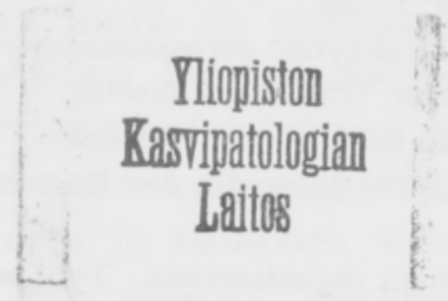

